\title{
Cycloaddition reaction of furan with $\mathrm{Si}(100)-2 \times 1$
}

M. H. Qiao, F. Tao, Y. Cao, Z. H. Li, W. L. Dai, J. F. Deng, and G. Q. Xu

Citation: J. Chem. Phys. 114, 2766 (2001); doi: 10.1063/1.1338477

View online: https://doi.org/10.1063/1.1338477

View Table of Contents: http://aip.scitation.org/toc/jcp/114/6

Published by the American Institute of Physics

\section{Articles you may be interested in}

Covalent attachment of acetonitrile on $\mathrm{Si}(100)$ through $\mathrm{Si}-\mathrm{C}$ and $\mathrm{Si}-\mathrm{N}$ linkages

The Journal of Chemical Physics 115, 8563 (2001); 10.1063/1.1410388

Coordination and reaction mechanism of furan on $\mathrm{Ru}(001)$

The Journal of Chemical Physics 111, 8068 (1999); 10.1063/1.480140

Studies of multichannel rotational predissociation of $\mathrm{Ar}-\mathrm{H}_{2}$ van der Waals molecule by the complex-coordinate coupled-channel formalism

The Journal of Chemical Physics 76, 5307 (1982); 10.1063/1.442929

Nonadiabatic approach for resonant molecular multiphoton absorption processes in intense infrared laser fields The Journal of Chemical Physics 79, 4708 (1983); 10.1063/1.445612

Simulation of sound propagation over porous barriers of arbitrary shapes

The Journal of the Acoustical Society of America 137, 303 (2015); 10.1121/1.4904553

Nanolamellar magnetoelectric $\mathrm{BaTiO}_{3}-\mathrm{CoFe}_{2} \mathrm{O}_{4}$ bicrystal

Applied Physics Letters 95, 153504 (2009); 10.1063/1.3241999

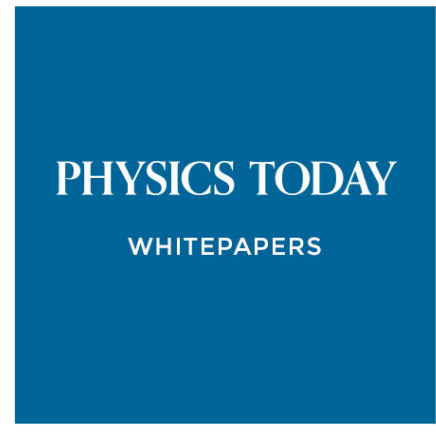

ADVANCED LIGHT CURE ADHESIVES

Take a closer look at what these environmentally friendly adhesive systems can do

\section{READ NOW}

PRESENTED BY (8) MASTERBOND० 


\title{
Cycloaddition reaction of furan with $\mathrm{Si}(100)-2 \times 1$
}

\author{
M. H. Qiao \\ Department of Chemistry, National University of Singapore, 10 Kent Ridge, Singapore 119260, Singapore \\ and Department of Chemistry, Fudan University, Shanghai 200433, People's Republic of China \\ F. Tao \\ Department of Chemistry, National University of Singapore, 10 Kent Ridge, Singapore 119260, Singapore \\ Y. Cao \\ Department of Chemistry, National University of Singapore, 10 Kent Ridge, Singapore 119260, Singapore \\ and Department of Chemistry, Fudan University, Shanghai 200433, People's Republic of China
}

Z. H. Li, W. L. Dai, and J. F. Deng

Department of Chemistry, Fudan University, Shanghai 200433, People's Republic of China

G. Q. Xua)

Department of Chemistry, National University of Singapore, 10 Kent Ridge, Singapore 119260, Singapore

(Received 13 June 2000; accepted 14 November 2000)

\begin{abstract}
The adsorption configuration of furan on $\mathrm{Si}(100)-2 \times 1$ at $125 \mathrm{~K}$ has been investigated using $\mathrm{X}$-ray photoelectron spectroscopy (XPS), ultraviolet photoelectron spectroscopy (UPS), high resolution electron energy loss spectroscopy (HREELS), and semiempirical molecular orbital (MO) calculation. A chemisorbed furan species is identified, which does not desorb until $300 \mathrm{~K}$. Our results clearly demonstrate the covalent attachment of furan onto $\mathrm{Si}(100)$, possibly through a [4+2] cycloaddition reaction. Based on the frontier molecular orbital (FMO) theory and work function measurements, an electron donation mechanism from furan to $\mathrm{Si}(100)-2 \times 1$ is proposed to be involved in the cycloaddition reaction. (C) 2001 American Institute of Physics. [DOI: $10.1063 / 1.1338477]$
\end{abstract}

\section{INTRODUCTION}

There is a growing interest in developing new functional surfaces and molecular devices using organic thin films. ${ }^{1}$ Particularly, the combination of organic thin films with technologically important silicon is becoming the focus of study due to its potential practical applications in the semiconductor industry. ${ }^{2,3}$ Such modified silicon surfaces are expected to have tailor-made electronic, optical or biofunctional properties by adopting proper organic reactants with different functional groups or chain lengths.

One of the pathways for silicon modification is to yield stable $\mathrm{Si}-\mathrm{C}$ bonds between organic molecules and silicon substrates. Formation of $\mathrm{Si}-\mathrm{C}$ bonds can be achieved by the Langmuir-Blodgett (LB) techniques or by the methodologies developed by Linford and Chidsey et al. through olefin insertion into the $\mathrm{H}-\mathrm{Si}$ bond of the hydrogenated silicon surfaces, ${ }^{4-8}$ or replacement of $\mathrm{Cl}$ on the $\mathrm{Cl}-\mathrm{Si}(111)$ surface by an alkyl group from an alkyllithium reagent. ${ }^{6,9}$ Furthermore, specifically for $\mathrm{Si}(100)$, it was found that its interaction with gaseous unsaturated organic molecules is rather facile with di- $\sigma$ bond formation. One of the thoroughly studied molecules is ethylene, which bonds to the surface via breakage of the $\pi$-bond and formation of two new $\mathrm{Si}-\mathrm{C}$ $\sigma$-bonds. ${ }^{10-14}$ Such coupling reactions involving two $\pi$-electrons of the molecule and two $\pi$-electrons of the silicon surface dimer are known as $[2+2]$ cycloaddition reac-

${ }^{a)}$ Author to whom correspondence should be addressed. tions. Although it is symmetry forbidden without photon excitation, ${ }^{15,16}$ this type of reaction is found to occur readily in practice. The contradiction may be compromised by introducing the radical mechanism or via low-symmetry intermediates.

Recently, based on the B3LYP hybrid Hartree-Fock/ density functional method, Konecny and Doren predicted a novel [4+2] cycloaddition pathway of diene on $\mathrm{Si}(100)-2 \times 1$ with surface $\mathrm{Si}$ dimers as dienophiles. ${ }^{17}$ Their theoretical study on 1,3-cyclohexadiene, 1,3-butadiene, and 2,3dimethyl-1,3-butadiene demonstrates that the [4+2] cycloadducts are thermodynamically more stable than the $[2+2]$ products. The resulting [4+2] cycloadduct has a sixmembered $\mathrm{Si}_{2} \mathrm{C}_{4}$ ring structure with $\mathrm{Si}-\mathrm{Si} \sigma$-bond remained. This prediction was readily verified by MIR-FTIR and NEXAFS studies for 1,3-butadiene and 2,3-dimethyl-1,3butadiene on the $\mathrm{Si}(100)-2 \times 1$ surface. $^{18,19}$ Thus a new way is opened for $\mathrm{Si}(100)$ modification. However, despite its practical significance in introducing another intact $\mathrm{C}=\mathrm{C}$ double bond at the interface available for further reaction, limited molecules have been checked within this theoretical framework. Besides the two chainlike conjugated molecules mentioned above and 1,3-cyclohexadiene, ${ }^{20,21}$ only benzene, an aromatic molecule, is experimentally and theoretically confirmed to undergo [4+2] cycloaddition when adsorbed on $\mathrm{Si}(100)$ at room temperature. ${ }^{22-25}$ In order to gain deeper insights into the generality of the prediction, it is necessary to extend the research regime to other conjugated systems such as five-membered heterocyclic aromatic molecules 
which function as building blocks of conductive polymers promising in microelectronics fabrication. ${ }^{26-29}$

In this paper, we present the adsorption behavior of furan on $\mathrm{Si}(100)-2 \times 1$ at $125 \mathrm{~K}$ using XPS, UPS, and HREELS. Two kinds of adsorbed species were identified, corresponding to chemisorbed and physisorbed furan. According to the line shape and binding energy shifts of the $\mathrm{C}(1 s)$ and $\mathrm{O}(1 s)$ XPS spectra and the loss features in HREELS, a covalently bonded geometry is proposed for chemisorbed furan. Furthermore, a higher absolute adsorption energy of the [4+2] cycloadduct was obtained as compared to the $[2+2]$ product by B3LYP/6-31G $(d) / / \mathrm{AM} 1 \mathrm{cal}-$ culations using a $9-\mathrm{Si}$ cluster.

\section{EXPERIMENT}

The experiments were performed in two UHV chambers both with a base pressure better than $2 \times 10^{-10}$ Torr. One of them is equipped with high resolution electron energy loss spectrometer (HREELS, LK2000). EELS measurements were taken in a specular geometry. The electron beam with an energy of $5.0 \mathrm{eV}$ impinges on the surface at an incident angle of $60^{\circ}$ with respect to the surface normal. A typical instrumental resolution of $5 \mathrm{meV}\left(40 \mathrm{~cm}^{-1}\right)$ is achieved. On the other chamber the core level spectra were recorded with a VG-CLAM 100 spectrometer operating with a nonmonochromatized $\mathrm{Al} k \alpha(h \nu=1486.6 \mathrm{eV})$ source and referenced to the binding energy $(\mathrm{BE})$ of $\mathrm{Si}(2 p)$ at $99.3 \mathrm{eV} .^{30}$ The pass energy for XPS was set as $20 \mathrm{eV}$, which gave the full width at half maximum (FWHM) of the $\mathrm{Si}(2 p)$ line of $\sim 1.15 \mathrm{eV}$. The valence band spectra were excited both by He I ( $h \nu$ $=21.2 \mathrm{eV})$ and He II $(h \nu=40.8 \mathrm{eV})$ and referenced to the Fermi level $\left(E_{F}\right)$ of the metallic tantalum sample holder. Because of the high secondary electron background, He I spectra were mainly used to extract information about work function variation when increasing furan exposures. For UPS the pass energy was set as $10 \mathrm{eV}$.

The $\mathrm{Si}(100)$ samples were cut from $p$-type silicon wafers (99.999\% pure, boron-doped, resistivity $1-30 \Omega \mathrm{cm}$, Goodfellow) and were mounted as following. Two pieces of $\mathrm{Si}(100)$ single crystals of the same dimension $(18 \times 10$ $\times 0.38 \mathrm{~mm}^{3}$ ) were evaporated with a thin Ta layer on their unpolished backside first for homogeneous heating and cooling. A piece of Ta foil $(99.9 \%$ pure, $0.025 \mathrm{~mm}$ thick, Goodfellow) was then sandwiched between the two as-treated silicon samples. The samples were clamped together by two Ta clips for fixation. The in-between Ta foil was spot-welded to two Ta rods connected to the manipulator. A 0.003 in. $\mathrm{W}-5 \% \mathrm{Re} / \mathrm{W}-26 \% \mathrm{Re}$ thermocouple (Type C) was attached to the center of one piece of the silicon sample using high temperature ceramic adhesive (Aremco 516) for temperature measurement and control. Such mounted silicon sample can be resistively heated to $1400 \mathrm{~K}$ and conductively cooled to $125 \mathrm{~K}$ using liquid nitrogen. The temperature distribution on the sample was within $\pm 10 \mathrm{~K}$ at $1000 \mathrm{~K}$ as identified by an IR pyrometer.

The silicon sample was then thoroughly degassed at 900 $\mathrm{K}$ for overnight under ultrahigh vacuum. Surface contaminants, such as carbon and oxygen were removed by repeated $\mathrm{Ar}^{+}$bombardment and annealing to $1300 \mathrm{~K}$. Surface clean- liness was confirmed by XPS, UPS, and HREELS. Furan (99+\%, Aldrich) and 2,3-dihydrofuran (2,3-DHF) (99\%, Aldrich) were purified by freeze-pump-thaw cycles prior to use. Dosing was accomplished by backfilling through a variable leak valve without ion gauge sensitivity calibration.

In order to obtain a detailed geometric information, the PM3 (Ref. 31) program, a part of the SPARTAN computational package, ${ }^{32}$ was employed to compute the fully optimized structures of furan chemisorbed on a five-layer $21-\mathrm{Si}$ cluster. Both the [4+2] [Fig. 1(a)] and [2+2] [Fig. 1(b)] configurations were taken into account in the calculation for comparison. Further, density of states for both configurations were derived by convoluting the calculated eigenvalues with a Gaussian function with a full width at half maximum (FWHM) of $1.0 \mathrm{eV}$ to take account of the resolution of the UPS system and the solid-state broadening effects. As the valence band of $\mathrm{Si}$ extends over a range of more than $12 \mathrm{eV}$, its overlapping with that of furan will lead to substantial intermixing of the orbitals. Thus some rehybridized orbitals contain so little adsorbate admixtures that their contributions to the photoelectron signal are usually shadowed in the background. ${ }^{22}$ Following this argument, in our simulation only orbitals with the Mulliken populations on the adsorbate higher than $10 \%$ were considered. Similar approach was employed for chemisorbed 1,4-phenylenediamine on $\mathrm{Si}(100)$ by Kugler et al., ${ }^{33}$ showing excellent agreement with experiments. On the other hand, as the PM3 or AM1 semiempirical method is parameterized mainly for obtaining an equilibrium structure, ${ }^{34}$ B3LYP, ${ }^{35}$ a hybrid density functional method implemented in the GAUSSIAN 94 computational package ${ }^{36}$ using a $6-31 \mathrm{G}(d)$ basis $\operatorname{set}^{37}$ was adopted here to compute the single point energy after obtaining the optimized structure by AM1 (Ref. 38) (B3LYP/6-31G(d)//AM1 level). Such a procedure can provide fast and reliable results for large molecular systems. ${ }^{39}$ In this case, a 9-Si cluster identical to Ref. 17 was employed.

\section{RESULTS AND DISCUSSION}

\section{A. X-ray photoelectron spectroscopy}

$\mathrm{X}$-ray photoelectron spectroscopy measurements were employed to investigate the chemical states, adsorption and desorption behavior of furan on $\mathrm{Si}(100)-2 \times 1$. Figure 2 shows the $\mathrm{C}(1 s)$ and $\mathrm{O}(1 s)$ spectra of furan adsorbed on $\mathrm{Si}(100)$ at $125 \mathrm{~K}$. Due to its high volatility of furan under vacuum and the thermal effect of the x-ray source, the physisorbed spectra can not be readily resolved to aid in direct comparison. However, the chemisorption character for furan is clearly evidenced by UPS spectrum shown in Fig. 6(f) which exhibits substantial difference from that of condensed furan on $\mathrm{Ru}(001)$ (Ref. 40) or gas phase spectrum. ${ }^{41}$ Figure 2 (a) is a typical $\mathrm{C}(1 s)$ spectrum of furan on $\mathrm{Si}(100)$ at $125 \mathrm{~K}$ (furan dosage $1.0 \mathrm{~L}, 1 \mathrm{~L}=1 \times 10^{-6}$ Torr s). We noticed that the $\mathrm{C}(1 s)$ spectrum is quite symmetric in line shape with two maxima. When fitting this peak, we employed the Voigt function and the least squares approach (by introducing the fit parameter, reduced chi-square) to determine the quality of the fitting. The number of component peaks is iteratively increased until the reduced chi-square is less than or equal to 
(a)

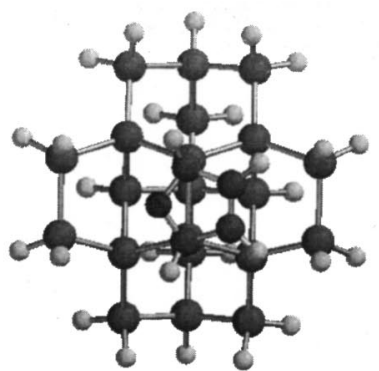

[1]̄0]

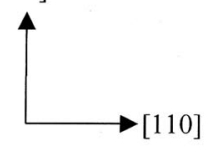

(b)

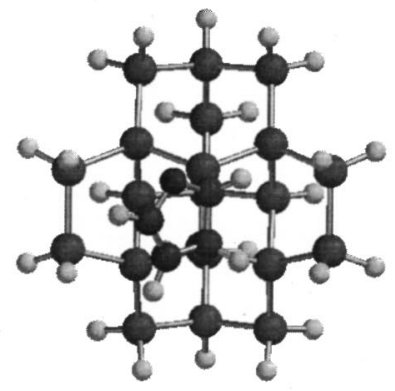

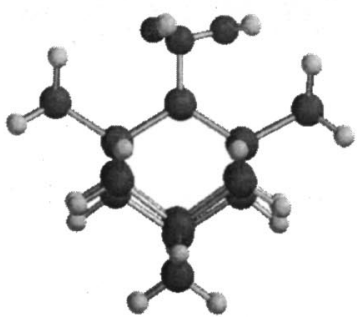

[100]
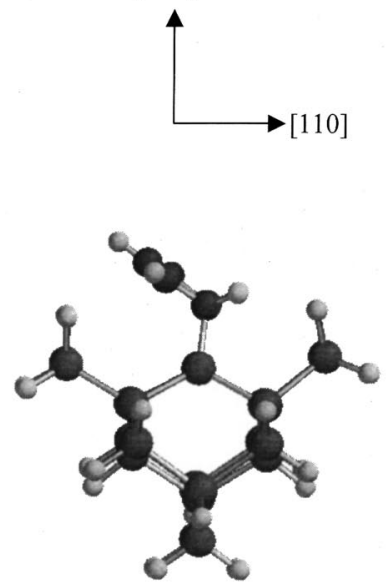

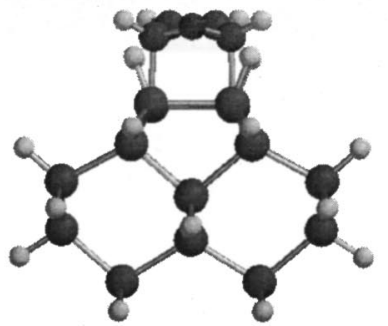

[100]
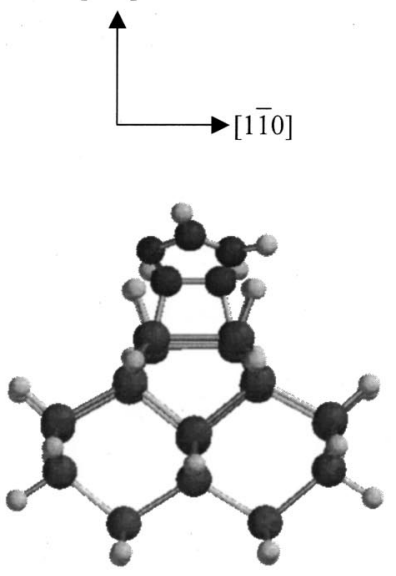

FIG. 1. Two possible bonding configurations for furan on a 21-Si cluster: (a) $[4+2]$ and (b) $[2+2]$ cycloadducts.

1 , thereby achieving a good quality fit with the minimum number of statistically justifiable peaks. We found that this procedure gives two peaks with identical peak height and width (FWHM $\sim 1.25 \mathrm{eV}$ ), implying the existence of two kinds of chemically inequivalent carbons but of equimole. The BEs of the fitted peaks are at 284.7 and $285.5 \mathrm{eV}$, respectively. The corresponding $\mathrm{O}(1 s)$ spectrum shows a single sharp peak at $\sim 532.4 \mathrm{eV}$. The $\mathrm{C}(1 s)$ BEs found here are thus quite different from those of physisorbed furan on $\operatorname{Ag}(110),{ }^{42}$ in which two $\mathrm{C}(1 s)$ peaks are located at 285.2 and $286.4 \mathrm{eV}$, corresponding to the $\beta$ - and $\alpha$-carbons in the furan ring. For $\mathrm{O}(1 s)$ of physisorbed furan, the BEs were found within $534.1-535.8 \mathrm{eV},{ }^{40,42,43}$ at least $1.7 \mathrm{eV}$ higher than the present observation. The chemisorption of furan may undergo through $[4+2]$ or/and $[2+2]$ cycloaddition reactions. However, the predominance of the $[2+2]$ cycloadduct would lead to a diffuse and asymmetric $\mathrm{C}(1 s)$ feature based on the electronegativity argument successfully applied by Hamers's group. ${ }^{44,45}$ We have also deposited physisorbed 2,3-DHF on $\mathrm{Si}(100)$ at $125 \mathrm{~K}$ and found that the $\mathrm{C}(1 s)$ peak is quite broad and asymmetric, which seems to support the formation of the [4+2] cycloadduct for furan on $\mathrm{Si}(100)$.

Figure 3 shows the areas of the $\mathrm{C}(1 s)$ and $\mathrm{O}(1 s)$ photoelectron peaks plotted as a function of furan exposures on $\mathrm{Si}(100)-2 \times 1$ at $125 \mathrm{~K}$. It is found that both $\mathrm{C}(1 s)$ and $\mathrm{O}(1 s)$ peak areas reach their maxima at $2.5 \mathrm{~L}$ exposure and increases very slowly at higher exposures. The small increase is due to the weak adsorption of physisorbed furan at $125 \mathrm{~K}$.
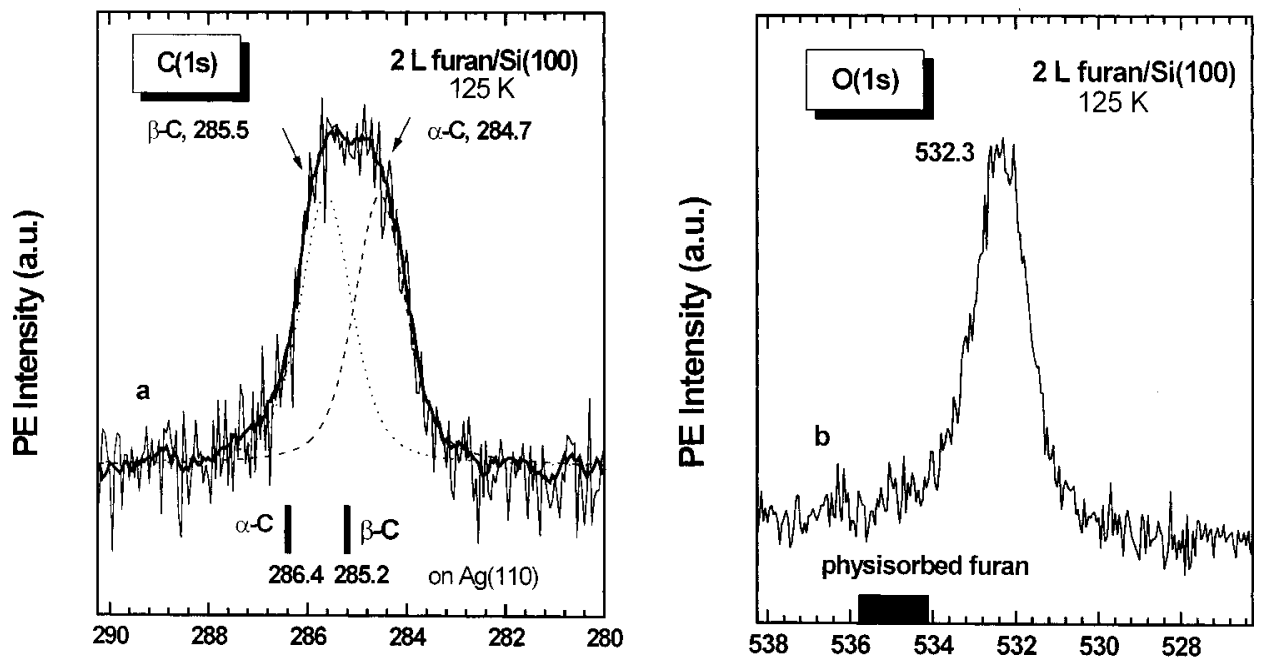

FIG. 2. Typical $\mathrm{C}(1 s)$ (a) and $\mathrm{O}(1 s)$ (b) XPS spectra for chemisorbed furan on $\mathrm{Si}(100)-2 \times 1$ at $125 \mathrm{~K}$. Furan dosage $1.0 \mathrm{~L} ; h \nu=1486.6 \mathrm{eV}$; pass energy $=20 \mathrm{eV}$. 


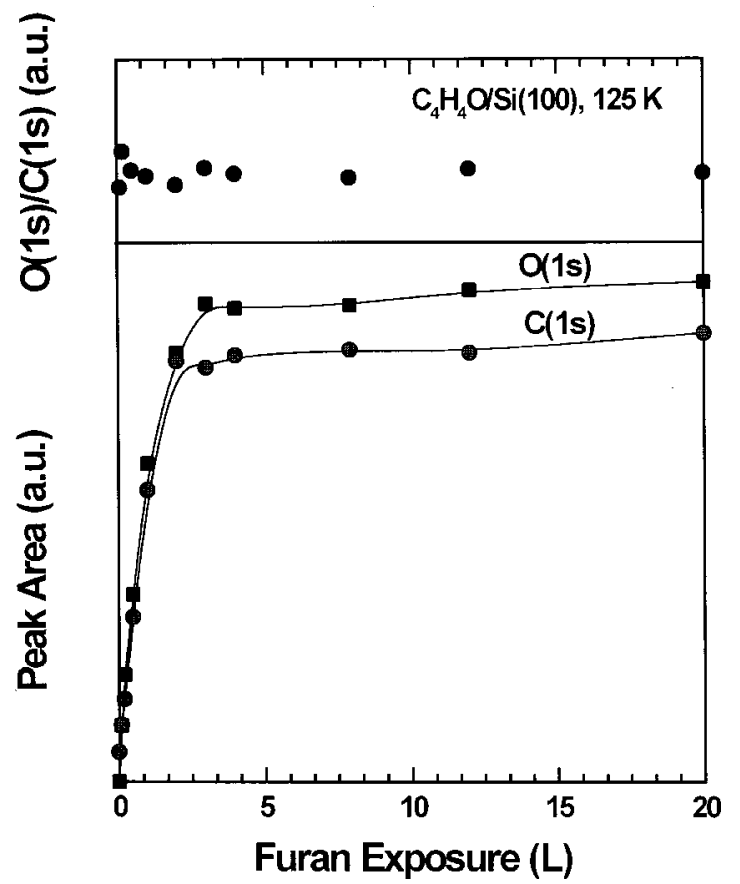

FIG. 3. The $\mathrm{C}(1 s)$ and $\mathrm{O}(1 s)$ XPS peak intensities (Bottom) and their intensity ratio (upper) as a function of furan exposures on $\mathrm{Si}(100)-2 \times 1$ at $125 \mathrm{~K} . h \nu=1486.6 \mathrm{eV}$; pass energy $=20 \mathrm{eV}$.

The nearly invariant adsorption rate towards saturation with increasing furan coverage is a common feature in adsorption of unsaturated hydrocarbons on the $\mathrm{Si}(100)-2 \times 1$ surface, characteristic of precursor-mediated chemisorption. ${ }^{12,46}$ The saturation of the $\mathrm{C}(1 s)$ and $\mathrm{O}(1 s)$ peak areas indicates the completion of the chemisorbed monolayer. The $\mathrm{C}(1 s)$ $\mathrm{O}(1 s)$ peak area ratio remains virtually constant from exposures as low as $0.1 \mathrm{~L}$ to as high as $20 \mathrm{~L}$. In order to exploit the stoichiometry of the chemisorbed species, a physisorbed 2,3-DHF layer of $\sim 20 \AA$ thick was used as a reference with the assumption that the $\mathrm{C}(1 s)$ and $\mathrm{O}(1 s)$ cross sections and scattering in both molecules are identical. It gives a $\mathrm{C} / \mathrm{O}$ molar ratio of 4.15 for the chemisorbed furan layer, consistent with the stoichiometry of intact furan molecules.

To estimate the saturation coverage [relative to the surface atomic density of $\mathrm{Si}(100)-2 \times 1$ ] of chemisorbed furan, a benzene-saturated surface at $300 \mathrm{~K}$ was measured with the same instrumental set-up. It is well known that the saturation coverage of benzene is $\sim 0.27 .^{47}$ The $\mathrm{C}(1 s) / \mathrm{Si}(2 p)$ intensity ratio for furan saturated $\mathrm{Si}(100)$ is calculated to be $\sim 0.36$, whereas the ratio for benzene saturated $\mathrm{Si}(100)$ to be $\sim 0.27$. A simple calculation by considering the number of $\mathrm{C}$ atoms in each molecule gives $\theta_{\text {furan }}$ of $\sim 0.54 \quad\left[\theta_{\text {furan }}=(0.27\right.$ $\times 0.36 / 4) /(0.27 / 6)]$, implying that one furan molecule corresponds approximately to one silicon dimer. From the stoichiometry and saturation coverage of the chemisorbed furan, it can be readily concluded that: (1) Furan does not dissociate into gaseous parts desorbing from the surface at $125 \mathrm{~K}$, as this would lead the $\mathrm{C} / \mathrm{O}$ molar ratio to appreciably deviate from 4. (2) At least furan does not dissociate into more than two parts that still reside on the surface, as this would lead to a saturation coverage of $<0.5$. Actually dissociative chemisorption on $\mathrm{Si}(100)-2 \times 1$ results in the forma-

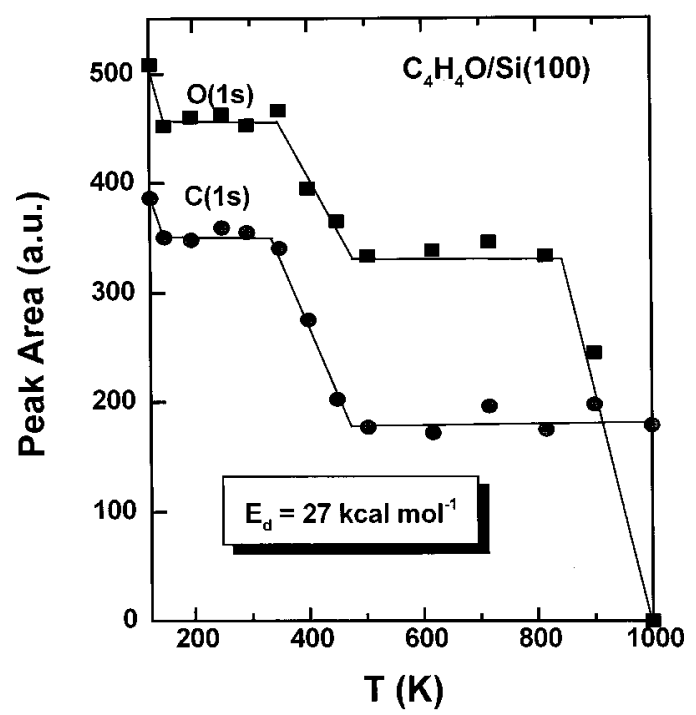

FIG. 4. Plot of $\mathrm{C}(1 s)$ and $\mathrm{O}(1 s)$ peak areas obtained after annealing the 20 $\mathrm{L}$ furan pre-exposed $\mathrm{Si}(100)-2 \times 1$ surface at $125 \mathrm{~K}$ to various temperatures. $h \nu=1486.6 \mathrm{eV}$; pass energy $=20 \mathrm{eV}$.

tion of $1 /(2 n)$ monolayers of adsorbate molecules, with $n$ being the number of bonds dissociated per molecule. ${ }^{48}$ Only one cracking pattern may account for all the observations mentioned above, i.e., furan undergoes direct deoxygenation as soon as it impinges on the surface, forming a $\mathrm{C}_{4} \mathrm{Si}$ metallocyclelike ring with oxygen attached to another neighboring silicon atom, similar to desulphurization of thiophene on some transition metals. ${ }^{49}$ However, even on freshly cleaved Si(111)- $2 \times 1$ surface, deoxygenation of furan does not occur until $300 \mathrm{~K}^{50}$ Furthermore, the parallel decrease of the $\mathrm{C}(1 s)$ and $\mathrm{O}(1 s)$ intensities upon annealing a $20 \mathrm{~L}$ furan exposed surface from 350 to $500 \mathrm{~K}$ (Fig. 4) is not compatible with the desorption behavior of atomic oxygen which does not leave the $\mathrm{Si}(100)$ surface until $\sim 1000 \mathrm{~K} .{ }^{51}$ It should be noted that in Fig. 4 we did not observe the decrease of the $\mathrm{C}(1 s)$ signal above $800 \mathrm{~K}$ due to carbon atoms penetration into the bulk ${ }^{52}$ or clustering. ${ }^{53}$ This could be attributable to the desorption of physisorbed furan from the feedthrough connecting with the sample at elevated heating temperatures and its readsorption onto the sample surface.

The formation of the [4+2] 2,5-dihydrofuran-like cycloadduct [Fig. 1(a)] is able to account for the intact stoichiometry, the saturation coverage and the resulting two $\mathrm{C}(1 s)$ peaks. It can also rationalize the discrepancy between the BEs of $\mathrm{C}(1 s)$ and $\mathrm{O}(1 s)$ observed here and those of the physisorbed furan on $\mathrm{Ag}(110)$. Liu and Hamers ${ }^{44}$ have investigated the $\mathrm{C}(1 s)$ core level BEs of simple organic molecules bonded to $\mathrm{Si}(100)$. For alkenelike carbon atoms, it is found that $\mathrm{C}(1 s)$ generally lies at $\sim 285.4 \mathrm{eV}$, which is about 0.6-0.9 eV higher than its saturated counterpart while carbon atoms bonded directly to the silicon surface show BEs 0.7-0.8 eV lower than those not bonded directly to silicon, which is consistent with the electronegativity argument (Pauling electronegativities for $\mathrm{C}$ and $\mathrm{Si}$ are 2.50 and 1.90, respectively.). Then the $284.7 \mathrm{eV}$ peak can be ascribed to the two $s p^{3}$-rehybridized $\alpha$-carbons $\sigma$-bonded to the silicon dimer while their electron densities are somewhat lowered 


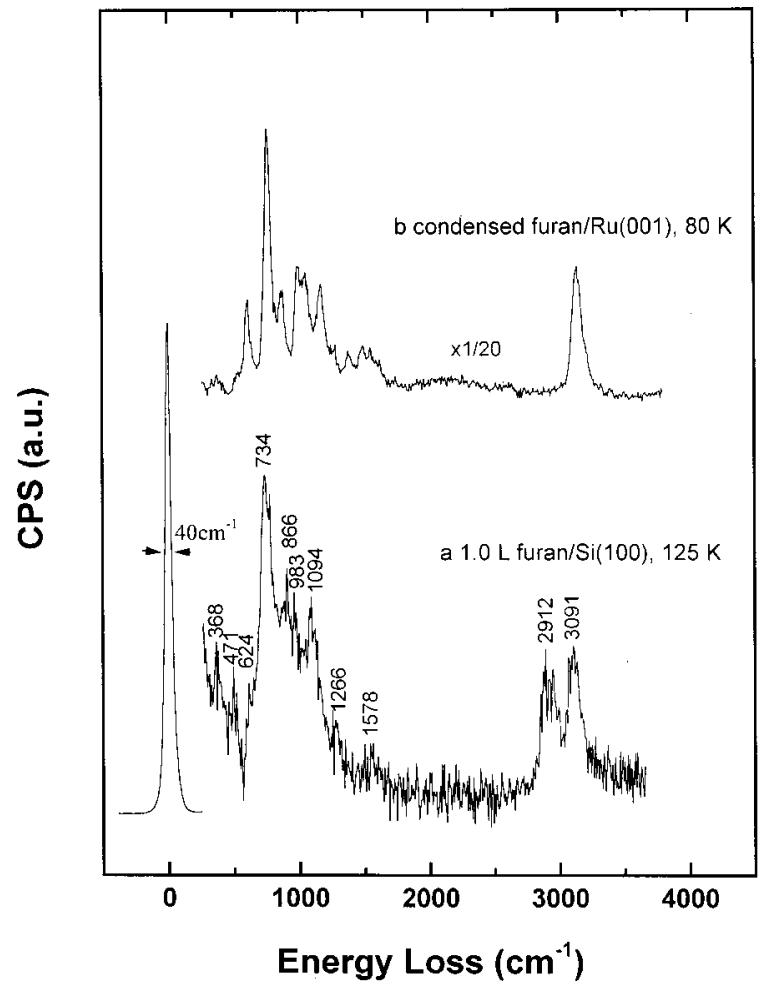

FIG. 5. HREELS spectra for (a) $1.0 \mathrm{~L}$ furan on $\mathrm{Si}(100)-2 \times 1$ at $125 \mathrm{~K}$ and (b) condensed furan on $\mathrm{Ru}(001)$ at $80 \mathrm{~K}$ for comparison. $E_{p}=5.0 \mathrm{eV}$, specular mode.

by the adjacent more electronegative oxygen (Pauling electronegativity 3.44). The $285.5 \mathrm{eV}$ peak can be ascribed to the two newly formed double-bonded $\beta$-carbons after [4+2] cycloaddition. It is further verified by the observation of the $285.5 \mathrm{eV}$ peak for $\beta$-carbons in multilayer 2,5-DHF on $\mathrm{Ag}(110)$ (Ref. 42) and $\mathrm{Si}(100) .{ }^{54}$ And in line with the formation of the [4+2] cycloadduct, the $\mathrm{O}(1 s) \mathrm{BE}$ falls in the range of $532.47-532.83 \mathrm{eV}$ characteristic of oxygen bonded to two aliphatic groups. ${ }^{55}$

\section{B. High resolution electron energy loss spectroscopy}

Figure 5(a) is the HREELS spectrum for $1.0 \mathrm{~L}$ furan exposed on $\mathrm{Si}(100)-2 \times 1$ at $125 \mathrm{~K}$. The vibrational spectrum for condensed furan on $\mathrm{Ru}(100)$ (Ref. 40) is also displayed for comparison [Fig. 5(b)]. As expected, the features of chemisorbed and physisorbed furan are in sharp contrast. Instead of a single $\nu(\mathrm{CH})$ loss peak at $3140 \mathrm{~cm}^{-1}$, for chemisorbed furan on $\mathrm{Si}(100)$ there is a doublet peaked at 2912 and $3091 \mathrm{~cm}^{-1}$ with nearly identical intensity, which are usually due to stretching of $s p^{3} \mathrm{C}-\mathrm{H}$ and $s p^{2} \mathrm{C}-\mathrm{H}$ bonds, respectively. The rehybridization of some carbons from $s p^{2}$ to $s p^{3}$ hybridized carbon suggests the loss of aromaticity of the furan ring when adsorbed on $\mathrm{Si}(100)$ at $125 \mathrm{~K}$. Previous EELS work for furan on cleaved $\mathrm{Si}(111)-2 \times 1$ at $85 \mathrm{~K}$ suggests the coexistence of a $\sigma$ - and a $\pi$-bonded species. ${ }^{50} \mathrm{How}$ ever, either in the $\sigma$-bonded or in the $\pi$-bonded species the aromaticity should sustain. The lack of the $\nu(\mathrm{SiH})$ mode in the present case readily excludes the formation of the $\sigma$-bonded species which involves $\mathrm{C}-\mathrm{H}$ bond scission and $\mathrm{Si}-\mathrm{H}$ bond formation.
TABLE I. Comparison of the vibrational modes of $1.0 \mathrm{~L}$ furan exposure on $\mathrm{Si}(100)-2 \times 1$ at $125 \mathrm{~K}$ with those of gaseous 2,5-dihydrofuran (2,5-DHF) (unit in $\mathrm{cm}^{-1}$ ).

\begin{tabular}{|c|c|c|}
\hline Gaseous 2,5-DHF ${ }^{\mathrm{a}}$ & $\begin{array}{l}\text { Chemisorbed furan } \\
\text { on } \operatorname{Si}(100)-2 \times 1\end{array}$ & Assignment $^{\mathrm{a}}$ \\
\hline 661.2 & 624 & $\gamma \mathrm{CC}-\mathrm{H}$ wag \\
\hline 739.7 & 734 & Ring def. \\
\hline \multicolumn{3}{|l|}{801} \\
\hline 901.5 & 866 & Ring str. \\
\hline \multicolumn{3}{|l|}{924} \\
\hline 982.6 & 983 & \\
\hline 1011.2 & & $\mathrm{CH}_{2}$ rock \\
\hline 1093 & 1094 & Ring str. \\
\hline 1097.0 & & Sym. $\Delta \mathrm{CC}-\mathrm{H}$ bend \\
\hline 1166.8 & & $\mathrm{CH}_{2}$ twist \\
\hline 1244 & 1266 & Sym. $\Delta \mathrm{CC}-\mathrm{H}$ bend + Ring pucker \\
\hline 1306 & & Asym. $\mathrm{CH}_{2}$ wag \\
\hline 1349 & & Asym. $\Delta \mathrm{CC}-\mathrm{H}$ bend \\
\hline 1362 & & Sym. $\mathrm{CH}_{2}$ wag \\
\hline 1480 & & Asym. $\mathrm{CH}_{2}$ sciss. \\
\hline 1489.7 & & $\mathrm{CH}_{2}$ sciss. \\
\hline 1626.4 & 1578 & $\mathrm{C}=\mathrm{C}$ str. \\
\hline 2864.4 & 2912 & $s p^{3} \mathrm{C}-\mathrm{H}$ str. \\
\hline 3095.8 & 3091 & $s p^{2} \mathrm{C}-\mathrm{H}$ str. \\
\hline
\end{tabular}

${ }^{\mathrm{a}}$ Reference 56.

As inferred by XPS, a direct comparison between the loss peaks of chemisorbed furan and the vibrational spectrum of gaseous 2,5-dihydrofuran ${ }^{56}$ is presented in Table I and good agreement is found. The formation of the [4+2] cycloadduct between furan and silicon dimer with two $\alpha$-carbons of furan rehybridized from $s p^{2}$ to $s p^{3}$ and bonded to a silicon dimer by forming two $\mathrm{Si}-\mathrm{C} \sigma$ bonds can account for the lack of the $\mathrm{CH}_{2}$-related loss features of 2,5dihydrofuran, as there is no $\mathrm{CH}_{2}$ group in the resulting cycloadduct. We ascribed the loss peak at $1578 \mathrm{~cm}^{-1}$ to the $\mathrm{C}=\mathrm{C}$ stretching mode between two doubly bonded $\beta$-carbons after [4+2] cycloaddition. For the 1,4cyclohexadienelike butterfly adsorption complex of benzene on $\mathrm{Si}(100)$, the $\nu(\mathrm{C}=\mathrm{C})$ mode was reported at $1623 \mathrm{~cm}^{-1} \cdot 25$ For the di- $\sigma$ bonded acetylene, the $\nu(\mathrm{C}=\mathrm{C})$ frequency of $\sim 1450 \mathrm{~cm}^{-1}$ was identified. ${ }^{14}$ Our frequency lies between these two values, which may result from the different steric effects within these adsorbate-substrate complexes. The loss peaks at 368 and $471 \mathrm{~cm}^{-1}$ are tentatively attributed to the hindered rotation/translation of the 2,5-dihydrofuranlike cycloadduct similar to that of the di- $\sigma$ bonded ethylene or acetylene on $\mathrm{Si}(100)-2 \times 1 .^{14}$

\section{Ultraviolet photoelectron spectroscopy}

UPS measurements were performed to probe the electronic interactions between adsorbed furan and the silicon substrate. Figure 6(a) is the He II spectrum for the clean $\mathrm{Si}(100)-2 \times 1$ surface. The photoelectron peak at $0.7 \mathrm{eV}$ below $E_{F}$ is due to the formation of the bonding "dangling bond" $\left(\pi_{b}\right)$ level according to the STM study of the occupied states of $\mathrm{Si}(100)$ by Hamers et al. ${ }^{57}$ Increasing furan exposures leads to the attenuation of the surface state and its total quenching at $\sim 2.0 \mathrm{~L}$ dosage. The loss of the surface state induced emission in the valence region must be caused 


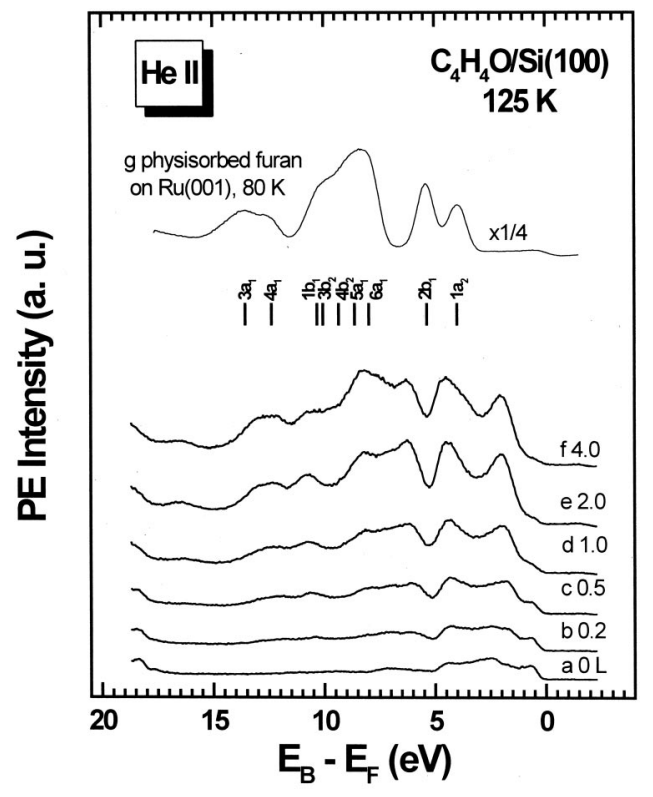

FIG. 6. He II $(h \nu=40.8 \mathrm{eV})$ UPS spectra of furan on $\mathrm{Si}(100)-2 \times 1$ as a function of furan exposures at $125 \mathrm{~K}$. The bar graph at the bottom of $(\mathrm{g})$ indicates the gas phase ionization potentials of furan (Ref. 41), which are shifted to align with the multilayer spectrum. Pass energy $=10 \mathrm{eV}$.

by the redistribution of its electron density in the resulting adsorbate-substrate complex. Meanwhile, adsorbateinduced emissions appear at $\sim 2.0,4.3,6.0,6.9,7.9,10.7$, and $12.1 \mathrm{eV}$ below $E_{F}$. For comparison, the UPS spectrum for condensed furan on $\mathrm{Ru}(001)$ at $80 \mathrm{~K}$ is shown as Fig. 6(g) and the orbital components are shown below Fig. 6(g) in the form of bar graph, which are rigidly shifted to account for work function and final state relaxation effects when condensed on the solid surface. Generally speaking, the first two sharp bands at 4.0 and $5.4 \mathrm{eV}$ for the physisorbed layer are of $\pi$ characters mainly localized on $\alpha$ - and $\beta$-carbons, respectively. And the following features are attributable to $\mathrm{C}-\mathrm{O}$, $\mathrm{C}-\mathrm{H}, \mathrm{C}-\mathrm{C} \sigma$-orbitals and oxygen nonbonding lone pair. ${ }^{41}$

The strong interaction between furan and $\mathrm{Si}(100)-2 \times 1$ leads to significant changes in the valence band spectrum as compared to the physisorbed features and that of a clean $\mathrm{Si}(100)$ surface. One of the most important deviations is the lack of the $\pi 1 a_{2}$ and $\pi 2 b_{1}$ bands in the chemisorbed spectrum, which strongly suggests substantial participation of the furan $\pi$-bonds in the formation of the adsorbate-surface complex. Combined with the depletion of the bonding "dangling bond" state, one can reasonably propose that chemisorption of furan on $\mathrm{Si}(100)$ mainly involves the furan $\pi$-bonds and the silicon dangling bonds. Instead of the elimination of the $\pi$ features, a new band at $\sim 1.9 \mathrm{eV}$ lower in BE than the $\pi 1 a_{2}$ level is formed. For benzene chemisorption, a new peak at $2.3 \mathrm{eV}$ below $E_{F}$ is observed on cleaved $\mathrm{Si}(111)-2 \times 1$ (Ref. 58) or $\mathrm{Si}(100)-2 \times 1$ (Ref. 22) and at 3.0 $\mathrm{eV}$ on $\mathrm{Si}(111)-7 \times 7 .{ }^{59}$ The occurrence of such a much shallower occupied molecular orbital is interpreted as splitting of the degenerated $\pi 1 e_{2 u}$ orbital by electron donation from the silicon substrate. This argument is compatible with the frontier molecular orbital (FMO) theory, in which the reactant pair that has the lowest energy difference between their fron-

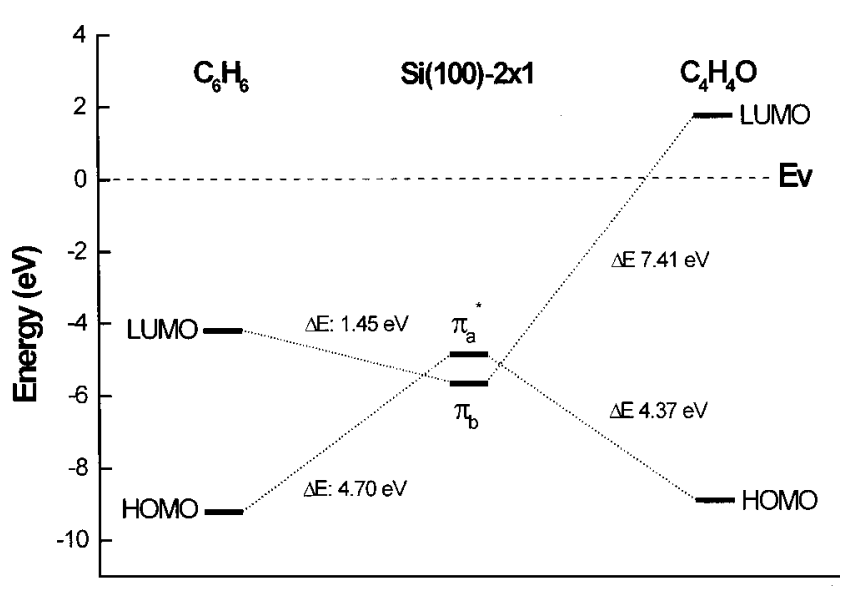

FIG. 7. Schematic orbital energy correlation diagram of frontier orbitals (HOMO and LUMO) of benzene and furan with $\mathrm{Si}(100)-2 \times 1$ bonding "dangling bond" $\left(\pi_{b}\right)$ and the antibonding "dangling bond" $\left(\pi_{a}^{*}\right)$ orbitals.

tier orbitals should be the most reactive. ${ }^{60}$ As illustrated in Fig. 7, for benzene the highest occupied molecular orbital (HOMO), $\pi 1 e_{1 g}$, lies at $9.2 \mathrm{eV}$ below $E_{v}$ (vacuum level) while the lowest unoccupied molecular orbital (LUMO), $\pi 1 e_{2 u}$, at $4.2 \mathrm{eV}$ below $E_{v}{ }^{59}$ By taking into account of the work function of $4.85 \mathrm{eV}$ for $\mathrm{Si}(100)-2 \times 1$, the bonding "dangling bond" $\left(\pi_{b}\right)$ level locates at $5.65 \mathrm{eV}$ below $E_{v}$ while the antibonding "dangling bond" $\left(\pi_{a}^{*}\right)$ at $4.50 \mathrm{eV}$ below $E_{v} \cdot{ }^{57}$ For symmetry consideration, only overlapping between $\mathrm{LUMO}_{\text {benzene }}$ and $\pi_{b, \mathrm{Si}}$ or $\pi_{a, \mathrm{Si}}^{*}$ and $\mathrm{HOMO}_{\text {benzene }}$ can result in stable chemical bonds. Referring to their energy differences $\Delta E s\left[\Delta E\left(\mathrm{LUMO}_{\text {benzene }}-\pi_{b, \mathrm{Si}}\right)\right.$ and $\Delta E\left(\pi_{a, \mathrm{Si}}^{*}\right.$ $\left.\left.-\mathrm{HOMO}_{\text {benzene }}\right)\right]$ of 1.45 and $4.70 \mathrm{eV}$, respectively, FMO theory readily justifies the direction of electron donation from the silicon $\pi_{b}$ level to the empty $\pi 1 e_{2 u}$ orbital of benzene, in agreement with the previous interpretation. However, it is not the case for furan chemisorption on $\mathrm{Si}(100)$. In Fig. 7 we also show the HOMO and LUMO energies for the gaseous furan molecule. ${ }^{41,61}$ Similarly, we obtain the energy differences $\Delta E s \quad\left[\Delta E\left(\mathrm{LUMO}_{\text {furan }}-\pi_{b, \mathrm{Si}}\right)\right.$ and $\Delta E\left(\pi_{a, \mathrm{Si}}^{*}\right.$ $\left.\left.-\mathrm{HOMO}_{\text {furan }}\right)\right]$ of 7.41 and $4.37 \mathrm{eV}$, respectively. Thus the inverse electron donation may happen for the furan $\mathrm{Si}(100)$ system, electrons flowing from the adsorbate to the substrate. This is not surprising, as five-membered heterocyclic aromatic molecules such as pyrrole, furan and thiophene are excessive in $\pi$-electrons as compared to benzene.$^{62}$ Furthermore, work function variation obtained from measuring the secondary electron cutoffs in the He I spectra for different furan exposures at $125 \mathrm{~K}$ is consistent with this argument. In Fig. 8, work function decreases sharply under furan exposures on $\mathrm{Si}(100)$ less than $2.5 \mathrm{~L}$, and then levels off at higher exposures, indicating electron donation from furan to the substrate. Thus we ascribe the newly formed low-lying valence band feature as downshift of the antibonding "dangling bond" level of $\mathrm{Si}(100)-2 \times 1$ in the present case.

\section{Semiempirical calculations}

While XPS, UPS, and HREELS can provide the electronic and vibrational properties of the surface-molecule complex, theoretical modeling can elucidate its structure at 


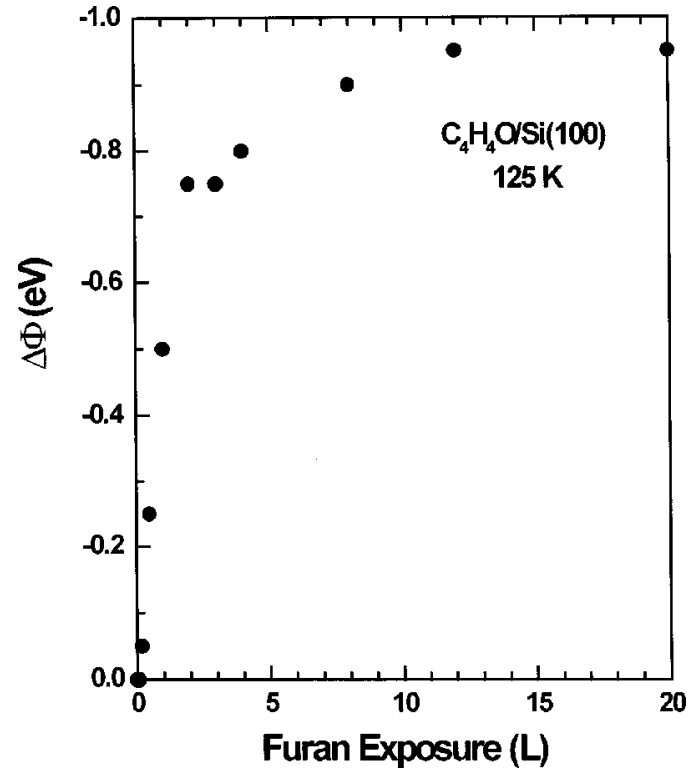

FIG. 8. Coverage-dependent work function variation of furan on $\mathrm{Si}(100)$ $2 \times 1$ at $125 \mathrm{~K}$.

the submolecular level. We have geometrically optimized the [4+2] cycloadduct as implied by the XPS and HREELS studies at the PM3 level by employing a five-layer 21-Si cluster. The resulted geometry is shown is Fig. 1(a) and its selected structural parameters are listed in Table II. According to the calculation, the predicted $\mathrm{Si}-\mathrm{Si}$ dimer bond length is $2.42 \AA$, which is slightly shorter than experimentally obtained intact $\mathrm{Si}-\mathrm{Si}$ bond on the $\mathrm{Si}(100)$ surface $(2.45-2.54$ $\AA){ }^{63}$ The $\mathrm{Si}-\mathrm{C}$ distances are $1.98 \AA$, similar to the calculated $\mathrm{Si}-\mathrm{C}$ bond lengths in ethylene adsorption product on $\operatorname{Si}(100)(1.93 \AA)$ or in calculated cycloadduct of 1,3 cyclohexadiene on $\mathrm{Si}(100)$ at the $\mathrm{B} 3 \mathrm{LYP} / 6-31 \mathrm{G}^{* *}$ level $(1.95 \AA),{ }^{16}$ but much longer than that in $\beta$-SiC crystal (1.89 $\AA) .{ }^{64}$ The $\mathrm{Si}-\mathrm{Si}-\mathrm{C}$ angle $\left(87.8^{\circ}\right)$ is smaller than the ideal tetrahedral value, however, it is much less distorted than the corresponding angles in the $[2+2]$ cycloadduct shown below. On the other hand, the bond lengths within the $\mathrm{C}_{4} \mathrm{O}$ ring change substantially. The bond between the neighboring $\mathrm{C}_{\alpha}$ and $\mathrm{C}_{\beta}$ atoms stretches from $1.361 \AA$ in the free furan molecule ${ }^{65}$ to $1.50 \AA$ in the $[4+2]$ cycloadduct, while the bond length between two $\beta$-carbon atoms shortens from

TABLE II. The selected geometrical parameters for the [4+2] cycloadduct of furan chemisorbed on $\mathrm{Si}(100)-2 \times 1$ surface at the PM3 theoretical level and the experimental bond lengths for intact furan and 2,5-dihydrofuran.

\begin{tabular}{lccc}
\hline \hline & {$[4+2]$ cycloadduct } & Furan $^{\mathrm{a}}$ & 2,5-dihydrofuran \\
\hline $\mathrm{Si}-\mathrm{Si}(\AA)$ & 2.415 & $\ldots$ & $\ldots$ \\
$\mathrm{Si}-\mathrm{C}_{\alpha}(\AA)$ & 1.976 & $\ldots$ & $\ldots$ \\
$\mathrm{C}_{\alpha}-\mathrm{C}_{\beta}(\AA)$ & 1.496 & 1.361 & 1.502 \\
$\mathrm{C}_{\beta}-\mathrm{C}_{\beta}(\AA)$ & 1.352 & 1.431 & 1.347 \\
$\mathrm{C}_{\alpha}-\mathrm{O}(\AA)$ & 1.433 & 1.362 & 1.440 \\
$\mathrm{Si}-\mathrm{C}_{\alpha}-\mathrm{O}\left(^{\circ}\right)$ & 105.6 & $\ldots$ & $\ldots$ \\
$\mathrm{Si}-\mathrm{C}_{\alpha}-\mathrm{C}_{\beta}\left({ }^{\circ}\right)$ & 102.2 & $\ldots$ & $\ldots$ \\
$\mathrm{Si}-\mathrm{Si}-\mathrm{C}_{\alpha}\left({ }^{\circ}\right)$ & 87.8 & $\ldots$ & $\ldots$ \\
\hline \hline
\end{tabular}

${ }^{\mathrm{a}}$ Reference 65.

${ }^{\mathrm{b}}$ Reference 66 .

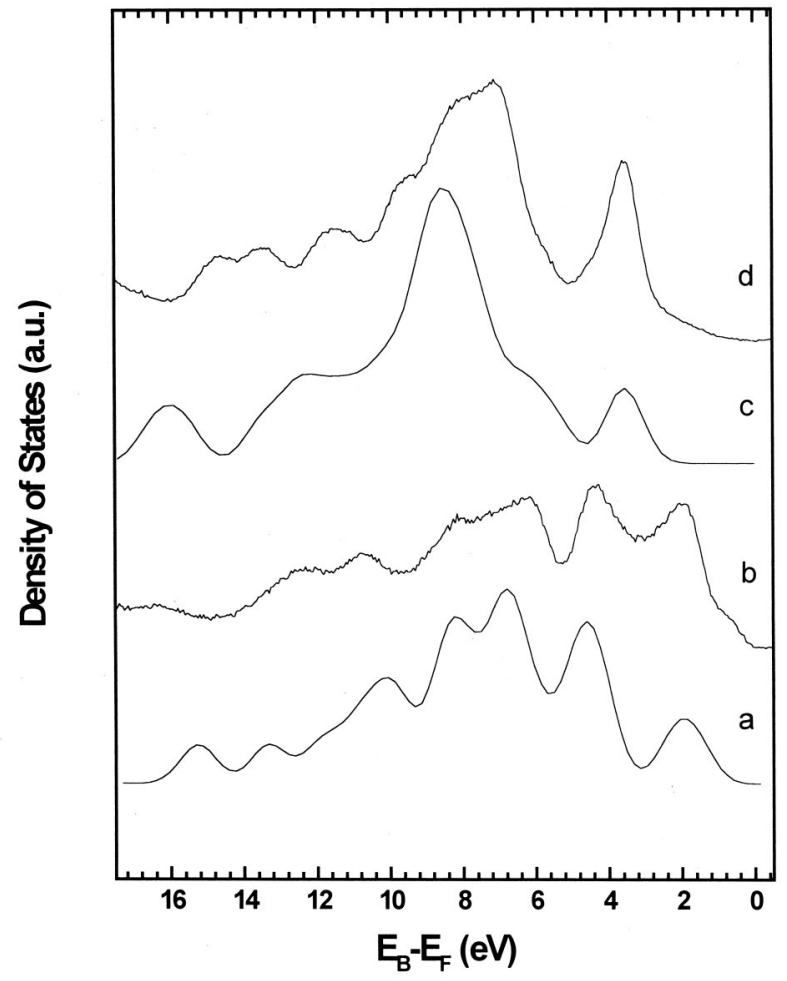

FIG. 9. Simulated DOS for furan on $\mathrm{Si}(100)-2 \times 1$ in (a) $[4+2]$, (c) $[2+2]$ configurations and experimental valence band spectrum for (b) chemisorbed furan and (d) multilayer 2,3-dihydrofuran on $\mathrm{Si}(100)-2 \times 1$ at $125 \mathrm{~K}$.

$1.431 \AA$ to $1.35 \AA$, typical of a $\mathrm{C}=\mathrm{C}$ double bond $(1.34 \AA$ in ethylene). The semiempirical calculation clearly indicates the rehybridization of the $\alpha$-carbons from $s p^{2}$ to $s p^{3}$ and the loss of aromaticity of the furan ring. Comparison with 2,5-dihydrofuran ${ }^{66}$ reveals a deviation in terms of bond lengths of less than $0.5 \%$.

The $[4+2]$ mechanism by which furan can react with $\mathrm{Si}(100)$ is further suggested by the close resemblance of the simulated DOS with the experimental valence band spectrum [see Fig. 9(a) and 9(b)]. To get a better fit between the experimental and simulated UPS spectra, the simulated spectrum is shifted down to account for work function and relaxation effects. Additionally, we have also tried the $[2+2]$ configuration of furan chemisorbed on $\mathrm{Si}(100)-2 \times 1$ as such a reaction pathway is a common practice for unsaturated hydrocarbons such as ethylene and acetylene. In this case, we do not want to give a detailed description of structure variation between free furan molecule and furan bonded in [2+2] geometry on $\mathrm{Si}(100)$. However, the high strain within the $[2+2]$ cycloadduct is noticed, as indicated by the two $\mathrm{Si}-$ $\mathrm{Si}-\mathrm{C}$ angles of $\sim 30^{\circ}$ smaller than the ideal tetrahedral angle. The simulated DOS for the [2+2] cycloadduct [Fig. 9(c)] also shows substantial deviation with the experimental spectrum while it is qualitatively similar to that of physisorbed 2,3-DHF on $\mathrm{Si}(100)-2 \times 1$ at $125 \mathrm{~K}$ [Fig. 9(d)]. ${ }^{54}$

Calculations at the B3LYP/6-31G(d)//AM1 level were carried out to obtain the adsorption energies for the [4+2] and $[2+2]$ cycloadducts between furan and $\mathrm{Si}(100)-2 \times 1$. Adsorption energies are extracted from the total energy of the molecule/cluster complex by subtracting the energies of 
the separated molecule and cluster. The resulted adsorption energies for the $[4+2]$ and $[2+2]$ cycloadducts are -32.79 and $-21.59 \mathrm{kcal} \mathrm{mol}^{-1}$, respectively. Thus the $[4+2] \mathrm{cy}-$ cloadduct is thermodynamically about $11 \mathrm{kcal} \mathrm{mol}^{-1}$ more stable than the $[2+2]$ product at the B3LYP/6-31G $(d) / /$ AM1 level. We take the center of the temperature range for molecular furan desorption observed by XPS as the peak maximum $(425 \mathrm{~K})$ and a heating rate of $1.5 \mathrm{~K} \mathrm{~s}^{-1}$. Assuming a first order desorption and a pre-exponential factor of $10^{13} \mathrm{~s}^{-1}$, Redhead formula ${ }^{67}$ gives the experimental desorption energy, $E_{d}$, of $27.0 \mathrm{kcal} \mathrm{mol}^{-1}$ for furan chemisorbed on $\mathrm{Si}(100)$. The difference between experimental and theoretical values in this study is rather comparable to that in the case of ethylene adsorption on $\mathrm{Si}(100)$ surface, in which, the experimental estimate of the desorption energy is 38.0 $\mathrm{kcal} \mathrm{mol}^{-1}$ (Ref. 12) while the calculated adsorption energy using a 9-Si cluster geometrically optimized at the B3LYP/6-31G** level is $-43.2 \mathrm{kcal} \mathrm{mol}^{-1}{ }^{16}$

In recent studies, ${ }^{45,68,69}$ Hamers et al. showed that a highly ordered organic layer can be formed via [2+2] cycloaddtion reaction between nonconjugated alkenes and silicon surface dimers. Thus it is possible to create organic films exhibiting anisotropy in their physical properties, which is promising in design of novel molecular devices. The unique bonding geometry is demanded for this purpose, as the presence of more than one bonding configuration almost always leads to disordered layers. If the $[4+2]$ cycloaddition reaction between dienes and silicon dimers undergoes as selective, it is even more desirable as there will be a $\mathrm{C}=\mathrm{C}$ double bond left for further modification while keeping the anisotropy. However, the STM and FTIR studies revealed that for 2,3-dimethyl-1,3-butadiene about $80 \%$ of molecules bond via the [4+2] pathway, while for 1,3-cyclohexadiene the ratio is even less, only about $55 \% .{ }^{20}$ Our finding shows that furan can also be attached onto the surface through a [4+2] cycloaddition reaction. It is worthwhile to note that furan has been used efficiently in this capacity since the early days of the Diels-Alder reaction. ${ }^{70}$

\section{CONCLUSIONS}

Furan is nondissociatively chemisorbed on the $\mathrm{Si}(100)$ $2 \times 1$ surface at $125 \mathrm{~K}$. Our results of XPS, UPS, HREELS, and semiempirical calculations are consistent with the formation of the $[4+2]$ cycloadduct, in which furan functions as diene and silicon surface dimers as dienophiles. The [4+2] furan-substrate complex is characterized by two $\mathrm{C}(1 s)$ peaks at 284.7 and $285.5 \mathrm{eV}$ with identical intensity and a single $\mathrm{O}(1 s)$ peak at $532.4 \mathrm{eV}$, which are far from the corresponding values in physisorbed furan. The rehybridization of carbons from $s p^{2}$ to $s p^{3}$ is also identified by HREELS. The bonding involves the furan $\pi 1 a_{2}$ and $\pi 2 b_{1}$ levels and the silicon surface bonding "dangling bond" state, as inferred by the quenching of these states in the UPS spectra when furan adsorbs on the surface. Semiempirical simulation of the valence band spectrum of the [4+2] cycloadduct shows close resemblance with the experimental result. The Frontier Molecular Orbital theory suggests that the bonding of furan on $\mathrm{Si}(100)-2 \times 1$ involves furan donating its HOMO electrons to the silicon substrate, as evidenced by the decrease in work function with increasing furan exposures. However, further experimental studies are required to unambiguously exclude the existence of the $[2+2]$ cycloadduct.

\section{ACKNOWLEDGMENT}

This work was supported by the National University of Singapore under Grant No. RP3981644.

${ }^{1}$ H. Fuchs, H. Ohst, and W. Prass, Adv. Mater. 3, 10 (1991).

${ }^{2}$ J. T. Yates, Jr., Science 279, 335 (1998).

${ }^{3}$ I. Amato, Science 282, 402 (1998).

${ }^{4}$ M. R. Linford and C. E. D. Chidsey, J. Am. Chem. Soc. 115, 12631 (1993).

${ }^{5}$ M. R. Linford, P. Fenter, P. M. Eisenberger, and C. E. D. Chidsey, J. Am. Chem. Soc. 117, 3145 (1995).

${ }^{6}$ J. Terry, M. R. Linford, C. Wigren et al., Appl. Phys. Lett. 71, 1056 (1997).

${ }^{7}$ J. Terry, M. R. Linford, C. Wigren et al., J. Appl. Phys. 85, 213 (1999).

${ }^{8}$ A. B. Sieval, A. L. Demirel, J. W. M. Nissink et al., Langmuir 14, 1759 (1998).

${ }^{9}$ A. Bansal, X. L. Li, I. Lauermann et al., J. Am. Chem. Soc. 118, 7225 (1996).

${ }^{10}$ J. Yoshinobu, H. Tsuda, M. Onchi, and M. Nishijima, J. Chem. Phys. 87, 7332 (1987).

${ }^{11}$ C. C. Cheng, R. M. Wallace, P. A. Taylor et al., J. Appl. Phys. 67, 3693 (1990).

${ }^{12}$ L. Clemen, R. M. Wallace, P. A. Taylor et al., Surf. Sci. 268, 205 (1992).

${ }^{13}$ W. Widdra, C. Huang, and W. H. Weinberg, Surf. Sci. 329, 295 (1995).

${ }^{14}$ W. Widdra, C. Huang, S. I. Yi, and W. H. Weinberg, J. Chem. Phys. 105, 5605 (1996).

${ }^{15}$ R. B. Woodward and R. Hoffmann, The Conservation of Orbital Symmetry (Academic, New York, 1970).

${ }^{16}$ R. Konecny and D. J. Doren, Surf. Sci. 417, 169 (1998).

${ }^{17}$ R. Konecny and D. J. Doren, J. Am. Chem. Soc. 119, 11098 (1997).

${ }^{18}$ A. V. Teplyakov, M. J. Kong, and S. F. Bent, J. Am. Chem. Soc. 119, 11100 (1997).

${ }^{19}$ A. V. Teplyakov, M. J. Kong, and S. F. Bent, J. Chem. Phys. 108, 4599 (1998).

${ }^{20}$ J. S. Hovis, H. Liu, and R. J. Hamers, J. Phys. Chem. B 102, 6873 (1998).

${ }^{21}$ J. S. Hovis, H. Liu, and R. J. Hamers, Surf. Sci. 402/404, 1 (1998).

${ }^{22}$ S. Gokhale, P. Trischberger, D. Menzel et al., J. Chem. Phys. 108, 5554 (1998).

${ }^{23}$ U. Birkenheuer, U. Gutdeutsch, and N. Rösch, Surf. Sci. 409, 213 (1998).

${ }^{24}$ M. J. Kong, A. V. Teplyakov, J. G. Lyubovitsky, and S.-F. Bent, Surf. Sci. 411, 286 (1998).

${ }^{25}$ M. Staufer, U. Birkenheuer, T. Belling et al., J. Chem. Phys. 112, 2498 (2000).

${ }^{26}$ H. Koezuda and S. Etoh, J. Appl. Phys. 54, 2511 (1983).

${ }^{27}$ A. Tsumura, L. Tossi, and H. E. Katz, Science 268, 270 (1995).

${ }^{28}$ Handbook of Conducting Polymers, edited by T. Skotheim (Dekker, New York, 1986).

${ }^{29}$ S. Glenis, M. Benz, E. LeGoff et al., J. Am. Chem. Soc. 115, 12519 (1993).

${ }^{30}$ Handbook of X-Ray Photoelectron Spectroscopy (Perkin-Elmer Corporation, Eden Pravie, 1992).

31 (a) J. J. P. Stewart, J. Comput. Chem. 10, 209 (1989); (b) 10, 221 (1989).

${ }^{32}$ SPARTAN 5.1, Wavefunction, Inc., Irvine CA, USA.

${ }^{33}$ Th. Kugler, U. Thibaut, M. Abraham et al., Surf. Sci. 260, 64 (1992).

${ }^{34}$ W. J. Hehre, J. Yu, and P. E. Klunzinger, A Guide to Molecular Mechanics and Molecular Orbital Calculations in SPARTAN, Wavefunction, Inc., Irvine CA, USA, 1997.

35 (a) C. Lee, W. Yang, and R. G. Parr, Phys. Rev. B 37, 785 (1988); (b) A. D. Becke, J. Chem. Phys. 98, 1372 (1993); (c) P. J. Stevens, F. J. Devlin, C. F. Chabalowski, and M. J. Frisch, J. Phys. Chem. 98, 11623 (1994).

${ }^{36}$ M. J. Frisch, G. W. Trucks, H. B. Schlegel et al., GAUSSIAN 94, Revision C. 2 (Gaussian, Inc., Pittsburgh, PA, 1995).

${ }^{37}$ M. J. Frisch, J. A. Pople, and J. S. Binkley, J. Chem. Phys. 80, 3265 (1984).

${ }^{38}$ M. J. S. Dewar, E. G. Zoebisch, E. F. Healy, and J. J. P. Stewart, J. Am. Chem. Soc. 107, 3902 (1985).

${ }^{39}$ (a) B. S. Jursic, J. Mol. Struct.: THEOCHEM 358, 139 (1995); (b) 365, 55 (1996); (c) 370, 85 (1996); (d) B. S. Jursic and B. LeBlanc, J. Heterocycl. 
Chem. 33, 1389 (1996); (e) B. S. Jursic, J. Chem. Soc., Perkin Trans. 2, 369 (1999); (f) J. S. Wright, D. J. Carpenter, D. J. McKay, and K. U. Ingold, J. Am. Chem. Soc. 119, 4245 (1997).

${ }^{40}$ F. Q. Yan, M. H. Qiao, X. M. Wei et al., J. Chem. Phys. 111, 8068 (1999).

${ }^{41}$ N. Kishimoto, H. Yamakado, and K. Ohno, J. Phys. Chem. 100, 8024 (1996).

${ }^{42}$ J. L. Solomon, R. J. Madix, and J. Stöhr, J. Chem. Phys. 94, 4012 (1991).

${ }^{43}$ D. T. Clark and C. M. J. Lilley, Chem. Phys. Lett. 9, 234 (1971).

${ }^{44}$ H. Liu and R. J. Hamers, Surf. Sci. 416, 354 (1998).

${ }^{45}$ M. D. Ellison, J. S. Hovis, H. Liu, and R. J. Hamers, J. Phys. Chem. 102, 8510 (1998).

${ }^{46}$ P. A. Taylor, R. M. Wallace, C. C. Cheng et al., J. Am. Chem. Soc. 114, 6754 (1992).

${ }^{47}$ Y. Taguchi, M. Fujisawa, T. Takaoka et al., J. Chem. Phys. 95, 6870 (1991).

${ }^{48}$ E. K. Hlil, L. Kubler, J. L. Bischoff, and D. Bolmont, Phys. Rev. B 35, 5913 (1987).

${ }^{49}$ B. C. Wiegand and C. M. Friend, Chem. Rev. 92, 491 (1992).

${ }^{50}$ M. N. Piancastelli, M. K. Kelly, G. Margaritondo et al., Surf. Sci. 211/ 212, 1018 (1989).

${ }^{51}$ T. Engel, Surf. Sci. Rep. 18, 91 (1993).

${ }^{52}$ H. N. Waltenburg and J. T. Yates, Jr. Chem. Rev. 95, 1589 (1995).

${ }^{53}$ F. Rochet, F. Jolly, F. Bournel et al., Phys. Rev. B 58, 11029 (1998).

${ }^{54}$ M. H. Qiao, F. Tao, J. F. Deng, and G. Q. Xu (unpublished results).

${ }^{55}$ High Resolution XPS of Organic Polymers (The Scienta ESCA300 Database), edited by G. Beamson and D. Briggs (Wiley, Chichester, 1992).

${ }^{56}$ T. D. Klots and W. B. Collier, Spectrochim. Acta, A 50, 1725 (1994).

${ }^{57}$ R. J. Hamers, Ph. Avouris, and F. Bozso, J. Vac. Sci. Technol. A 6, 508 (1988).
${ }^{58}$ M. N. Piancastelli, M. K. Kelly, Y. Chang et al., Phys. Rev. B 35, 9218 (1987).

${ }^{59}$ M. Carbone, M. N. Piancastelli, R. Zanoni et al., Surf. Sci. 407, 275 (1998).

${ }^{60}$ I. Fleming, Frontier Orbitals and Organic Chemical Reactions (Wiley, London, 1976), Chap. 4.

${ }^{61}$ A. F. Diaz, J. Crowley, J. Bargon et al., J. Electroanal. Chem. Interfacial Electrochem. 121, 355 (1981).

${ }^{62} \mathrm{~T}$. Eicher and S. Hauptmann, The Chemistry of Heterocycles (Thieme, Stuttgart, 1995), Chap. 5.

${ }^{63}$ B. W. Holland, C. B. Duke, and A. Paton, Surf. Sci. 140, L269 (1984); W. S. Yang, F. Jona, and P. M. Marcus, Phys. Rev. B 28, 2049 (1983); T. S. Shu, W. S. Yang, F. Jona, and P. M. Marcus, in The Structure of Surfaces, edited by M. A. Van Hove and S. Y. Tong (Springer, Berlin, 1985), p. 293; S. Y. Tong and A. L. Maldonado, Surf. Sci. 34, 90 (1973).

${ }^{64}$ J. D. H. Donnay and H. M. Ondik, Inorganic Compounds, Crystal Data, Determinative Tables, 3rd ed. (U. S. GPO, Washington, D.C., 1973), Vol. II.

${ }^{65}$ F. Mata, M. C. Martin, and G. O. Sörensen, J. Mol. Struct. 48, 157 (1978).

${ }^{66}$ K. Tamagawa and R. L. Hilderbrandt, J. Am. Chem. Soc. 106, 20 (1984).

${ }^{67}$ P. A. Redhead, Vacuum 12, 203 (1962).

${ }^{68}$ R. J. Hamers, J. S. Hovis, S. Lee et al., J. Phys. Chem. B 101, 1489 (1997).

${ }^{69}$ J. S. Hovis and R. J. Hamers, J. Phys. Chem. B 101, 9581 (1997).

${ }^{70}$ O. Diels, K. Alder, and E. Naujoks, Ber. Dtsch. Chem. Ges. B 62, 554 (1929); O. Diels and K. Alder, Justus Liebigs Ann. Chem. 490, 243 (1931). 